\title{
DECISIONES FINALES EMITIDAS POR LOS PANELES DE SOLUCIÓN DE CONTROVERSIAS, ESTABLECIDOS EN EL MARCO DE LOS CAPÍTULOS XIX Y XX DEL TRATADO DE LIBRE COMERCIO DE AMÉRICA DEL NORTE DURANTE 2001*
}

Conforme al artículo 2002 del Tratado de Libre Comercio de América del Norte (TLCAN), la Comisión de Libre Comercio ha establecido un secretariado integrado por tres secciones nacionales, cada una de ellas en las ciudades capitales de los países miembros del TLCAN. Su función es la de prestar asistencia y apoyo administrativo a la comisión, paneles, comités y grupos de trabajo establecidos conforme al propio tratado.

Durante el año 2001 se emitieron tres decisiones finales, de las cuales la emisión de una de ellas fue administrada por la sección mexicana, como secretariado responsable; dos por la sección estadounidense y ninguna por la canadiense. A continuación se presenta un resumen del sentido de cada una de ellas.

\section{SECCIÓN MEXICANA}

\section{Capítulo XIX}

Caso: Revisión de la Resolución Final de la Investigación Antidumping sobre las Importaciones de Jarabe de Maíz de Alta Fructuosa (JMAF), originarias de Estados Unidos de América.

* Fuente: Sección Mexicana del Secretariado de los Tratados de Libre Comercio. Para acceder a una versión completa de los textos de las decisiones finales, se puede acudir a las secciones nacionales del secretariado o visitar la página de Internet: http://www.nafta-sec-alena.org. 
Número de expediente: MEX-USA-98-1904-01.

Países involucrados: México y Estados Unidos de América.

Panel: Víctor Blanco Fornieles (México), Héctor Cuadra y Moreno (México), Howard N. Fenton (EUA), Saul L. Sherman (EUA) y Gustavo Vega Cánovas, presidente del panel (México).

Fecha de emisión de la decisión final: 3 de agosto de 2001.

\section{Decisión final:}

1. Las cuotas compensatorias, materia de esta controversia, fueron aplicadas desde enero de 1998.

2. La autoridad investigadora condujo dos investigaciones públicas, relacionadas con la supuesta amenaza de daño a la industria azucarera nacional, y emitió dos determinaciones de amenaza de daño esencialmente idénticas.

3. Se integraron dos expedientes administrativos sustanciales en estos procedimientos, los cuales estuvieron disponibles para su revisión.

4. En su resolución revisada, la autoridad investigadora revisó expresamente su razonamiento en respuesta a la determinación del órgano independiente de revisión de la Organización Mundial de Comercio, de que su resolución original sobre amenaza de daño no se encontraba sustentada en el expediente administrativo ni en el análisis correspondiente.

5. El panel determinó que en la resolución revisada de la autoridad investigadora aún no sustentaba su conclusión de que existía una amenaza de daño a la industria azucarera nacional, debido a la importación de JMAF en condiciones desleales de comercio.

6. Finalmente, el panel determinó que la autoridad investigadora tiene únicamente dos cursos de acción consistentes con la decisión del panel.

El panel, en consecuencia, determinó lo siguiente:

7. Toda vez que la autoridad investigadora no probó la amenaza de daño, la autoridad investigadora debe retirar inmediatamente las cuotas compensatorias impuestas a las importaciones de JMAF, originarias de Estados Unidos de América y devolver los derechos aplicados desde la imposición de dichas cuotas.

8. En caso de que la autoridad investigadora desee evaluar nuevamente la base y justificación — si es que existiera - utilizada para su determinación de amenaza de daño, consistente con las determinaciones del 
panel, y a la luz de los múltiples procedimientos ya terminados, proceder de conformidad.

9. La autoridad investigadora cuenta con 90 días para cumplir con la orden del panel y concluir el procedimiento relativo a este asunto.

\section{Capítulo XX}

No se integró ningún panel en el marco del capítulo XX del TLCAN.

\section{SECCIÓN ESTADOUNIDENSE}

\section{Capítulo XIX}

Caso: Revisión de la Resolución Final de la Investigación de Productos Laminados de Acero Cincados Resistentes a la Corrosión, procedente de Canadá.

Número de expediente: USA-CDA-98-1904-01.

Países involucrados: Estados Unidos de América y Canadá.

Panel: Bruce Aitken, presidente del panel (EUA), Dale Tursi (EUA), Martha Ries (EUA), Leon Trakman (CDA) y Wilhelmania Tyler (CDA).

Fecha de emisión de la decisión final: 20 de marzo de 2001.

\section{Decisión final:}

1. La autoridad investigadora requiere recalcular los costos de producción de Stelco, tomando en consideración el retorno de las ganancias hechas por Baycot a Stelco al final del año. El panel le requiere a la autoridad investigadora que le otorgue el método mediante el cual recalculó el costo de producción a la luz del retorno de dichas ganancias. Además, el panel también le requiere a la misma autoridad investigadora que explique su metodología, en razón de los requerimientos reglamentarios y en conformidad con la legislación, tal y como fue interpretada por el panel. Para llegar a tal interpretación, el panel tomó en cuenta tres elementos de interpretación jurídica: el primero, es una referencia a la Collateral Estoppel Doctrine;* el segundo, mediante una interpretación de la aplica-

* La doctrina Collateral Estoppel señala que previo a un juicio donde concurren las mismas partes, pero con diferente acción, si hay un veredicto rendido, éste deberá respetarse, por lo que un asunto particular resuelto en un juicio válido previo no podrá ser litigado por esas mismas partes en un proceso posterior. Cfr. Black, Henry C. et al., Black's law dictionarity, 6a. ed., St, Paul Minn., West Publishing Co., 1990, centennial edition (1981-1991), p. 261. 
ción del derecho internacional y, por último, la aplicación de la regla especial 19 de la USC párrafo 1677 b(f)(1)-(2).

2. La autoridad investigadora es requerida para revaluar la aplicación de la regla especial 19 de la USC párrafo 1677 (b)(f)(3), en razón del requerimiento que la autoridad investigadora ajusta o varía al precio de transferencia, de acuerdo con el nuevo cálculo realizado, y que se refiere en el párrafo anterior.

3. En su memorial de respuesta, la autoridad investigadora requiere una revisión para corregir cualquier error en el costo del crédito imputado y fecha de pago determinado, en virtud de la reclamación de Stelco. El panel concede el requerimiento y tal revisión.

4. La autoridad investigadora es requerida para que otorgue al panel la respuesta a las instrucciones recomendadas en un término de 60 días, contados a partir de la fecha de emisión de la recomendación.

\section{Capítulo $X X$}

Caso: Revisión de la Resolución Final de la Investigación de Servicio Transfronterizos e Inversión en el Sector de Transporte de Carga.

Número de expediente: USA-MEX-98-2008-01.

Países involucrados: Estados Unidos de América, México y Canadá (tercera parte).

Panel: Luis M. Díaz (México), David Gantz (EUA), Michael Hathaway (EUA), Martín Hunter, presidente del panel (EUA), y Alejandro Ogarrio (México).

Fecha de emisión del reporte final: 5 de febrero de 2001.

\section{Reporte final:}

1. El panel, por unanimidad, determinó que la negativa generalizada por parte de Estados Unidos de América, de revisar y considerar para aprobación de cualquier solicitud de autorización de transportistas de propiedad mexicana, para prestar los servicios de transporte transfronterizo, fue y continuó siendo un incumplimiento de las obligaciones de Estados Unidos de América, conforme al anexo I y al artículo 1203 del TLCAN. No se justifica una excepción a estas obligaciones en la frase "en circunstancias similares" de los artículos 1202 y 1203, o por las excepciones establecidas en el capítulo IX, o conforme al artículo 2101. 
2. El panel, por unanimidad, determinó que las insuficiencias del marco normativo mexicano no constituyen una base legal suficiente para que Estados Unidos de América mantenga una moratoria a la consideración de las solicitudes de autorización para operar en Estados Unidos de América, por parte de prestadores de servicio de autotransporte de propiedad mexicana o domiciliados en México.

3. El panel, además, por unanimidad determinó que Estados Unidos de América ha incumplido y continúa en incumplimiento de sus obligaciones conforme al anexo $i$ (Reservas en Relación con Medidas Existentes y Compromisos de Liberalización), el artículo 1102 (Trato Nacional en Servicios, Inversión y Asuntos Relacionados) y el artículo 1103 (Trato de Nación más Favorecida, en Servicios, Inversión y Asuntos Relacionados), para permitir que nacionales mexicanos inviertan en empresas estadounidenses que proporcionan transporte de carga internacional dentro de Estados Unidos de América.

Por otra parte, el panel no determinó:

4. Que las partes del TLCAN no puedan establecer el nivel de protección que consideren adecuado para lograr objetivos legítimos de normalización. El panel no estuvo en desacuerdo respecto a que la seguridad en los servicios de autotransporte es un objetivo legítimo de normalización. Tampoco el panel impuso alguna limitante a la aplicación de normas de seguridad establecidas debidamente, y aplicadas en cumplimiento de las obligaciones exigibles por las partes, conforme al TLCAN. Además, en vista de que la controversia analizada por el panel se refirió a la llamada prohibición “generalizada”, el panel no aprobó ni desaprobó las determinaciones anteriores que hayan tomado las autoridades normativas pertinentes, respecto a la seguridad de algún operador de camión individual, conductores o vehículos, sobre los cuales el panel no recibió escrito o evidencia alguna.

Por lo anterior, el panel recomendó lo siguiente:

5. Estados Unidos de América deberá llevar a cabo las acciones necesarias para que sus prácticas respecto a servicios e inversiones en materia de transporte transfronterizo cumplan con sus obligaciones, conforme a las disposiciones aplicables al TLCAN.

6. El panel señaló que el cumplimiento de Estados Unidos de América con sus obligaciones del TLCAN, no necesariamente significa que proporcione una determinación favorable a todas o a alguna cantidad específica de solicitudes de empresas de transporte de propiedad mexicana, 
cuando sea evidente que algún solicitante, o solicitantes en particular, no sean capaces de cumplir con las normas de transporte estadounidenses al operar en ese país.

7. De igual manera, a juicio del panel, puede ser razonable que una parte del TLCAN concluya que para garantizar que los prestadores de servicios de otro país del TLCAN cumplan con sus propias normas aplicables, sea necesario imponer a esos prestadores en particular procedimientos distintos.

8. Estas consideraciones no son aplicables respecto a la negativa de Estados Unidos de América a permitir que los nacionales mexicanos inviertan en empresas de ese país que transportan carga internacional dentro de él, ya que tanto México como Estados Unidos de América están de acuerdo en que dicha inversión no da lugar a cuestiones de seguridad.

\section{SECCIÓN CANADIENSE}

Debido a que los procedimientos activos en esta sección nacional no han llegado a la etapa procesal decisoria, durante el año 2001 no se dio ninguna decisión final en los paneles integrados en el marco del TLCAN. 